\title{
Secondary prevention of coronary artery disease in contemporary clinical practice
}

\author{
Piotr Jankowski ${ }^{1}$, Danuta Czarnecka ${ }^{1}$, Renata Wolfshaut-Wolak ${ }^{2}$, Radosław Łysek ${ }^{2}$, \\ Anna Łukaszewska ${ }^{1}$, Piotr Bogacki ${ }^{3}$, Janusz Grodecki ${ }^{4}$, Ewa Mirek-Bryniarska ${ }^{5}$, \\ Jadwiga Nessler ${ }^{6}$, Piotr Podolec ${ }^{7}$, Kalina Kawecka-Jaszcz ${ }^{1}$, Andrzej Pająk ${ }^{2}$ \\ ${ }^{1} 1^{\text {st }}$ Department of Cardiology and Hypertension, Institute of Cardiology, \\ Jagiellonian University Medical College, Krakow, Poland \\ ${ }^{2}$ Department of Clinical Epidemiology and Population Studies, Institute of Public Health, \\ Jagiellonian University Medical College, Krakow, Poland \\ ${ }^{3}$ Department of Cardiology, Ludwik Rydygier District Hospital, Krakow, Poland \\ ${ }^{4}$ Department of Cardiology, Gabriel Narutowicz Memorial General Hospital, Krakow, Poland \\ ${ }^{5}$ Department of Cardiology, Jozef Dietl Hospital, Krakow, Poland \\ ${ }^{6}$ Department of Coronary Disease, Institute of Cardiology, \\ Jagiellonian University, Medical College, Krakow, Poland \\ ${ }^{7}$ Department of Cardiac and Vascular Diseases, Institute of Cardiology, \\ Jagiellonian University Medical College, Krakow, Poland
}

\begin{abstract}
Background: The highest priority in preventive cardiology was given to patients with established coronary artery disease (CAD). The aim of the study was to assess the implementation of guidelines for secondary prevention in everyday clinical practice by evaluating control of the main risk factors and the cardioprotective medication prescription rates for patients, following their hospitalization for CAD.
\end{abstract}

Methods: Five hospitals with cardiology departments serving the city and its surrounding districts in southern part of Poland participated in the study. Consecutive patients aged $\leq 80$ years, hospitalized from January 12010 to April 312012 due to an acute coronary syndrome or for a myocardial revascularization procedure were recruited and interviewed 6-18 months after hospitalization.

Results: The medical records of 595 patients (mean age: $62.8 \pm 9.0$ years, 397 men and 198 women) were reviewed and included in the analyses. Proportions of medical records with available information on risk factors were high with the exception of total cholesterol levels as well as weight and height measurements, which were available in less than $80 \%$ of the hospital records. The prescription rate at discharge for antiplatelets was 99\%, beta-blockers (BB) $85 \%$, angiotensin converting enzyme inhibitors (ACEI) or sartans - 85\%, and lipid-lowering drugs - 94\%. Patients scheduled for coronary artery bypass grafting were significantly less often prescribed BB, ACEI or sartans, and lipid-lowering drugs. The proportion of patients with high blood pressure ( $\geq 140 / 90 \mathrm{~mm} \mathrm{Hg}$ ) 6-18 months after hospitalization was 47\%, with high

Address for correspondence: Piotr Jankowski, MD, PhD, $1^{\text {st }}$ Department of Cardiology and Hypertension, Jagiellonian University Medical College, ul. Kopernika 17, 31-501 Kraków, Poland, tel: +48 1242473 00, fax: +48 124247320 , e-mail: piotrjankowski@interia.pl

Received: 21.06.2014 Accepted: 06.08.2014 
LDL cholesterol level $(\geq 1.8 \mathrm{mmol} / \mathrm{L}) 73 \%$, and with a high $\mathrm{Hb} A_{1 C}$ level $(\geq 7.0 \%) 14 \%$, whereas $20 \%$ of participants were smokers and $80 \%$ were overweight. The proportion of patients taking an antiplatelet agent 6-18 months after hospitalization was 90\%, BB - 82\%, ACEI - or sartan 78\%, and lipid-lowering drug - 82\%. Overall, 33.9\% of the study participants declared that they had been advised to participate in a rehabilitation/secondary prevention program following their hospitalization and 30.5\% participated in a rehabilitation/secondary prevention program. However, only $28.2 \%$ took part in at least half of the planned sessions. Using a multivariate analysis we showed that, in general, risk factors control and the prescription rates of cardioprotective medications were related to the patients' age, education, and participation in a rehabilitation/secondary prevention program following their hospitalization due to CAD.

Conclusions: Our data provide evidence that there is a considerable potential for further reduction of cardiovascular risk in CAD patients. Our results suggest that increasing patient participation rates in rehabilitation/secondary prevention programs may improve the implementation of the secondary prevention. (Cardiol J 2015; 22, 2: 219-226)

Key words: coronary artery disease, risk factors, secondary prevention, smoking, hypertension, hypercholesterolemia

\section{Introduction}

Coronary artery disease (CAD) is the most common single cause of death in developed countries [1]. In Poland, the standardized death rate from ischemic heart disease in people under 65 years of age is 24 per 100,000 and the number of ischemic heart disease deaths is 45,000 yearly $[2,3]$. In recent years, rapid development in pharmacological as well as invasive CAD treatment methods has been observed. Nevertheless, the results of a mortality follow-up of the European Action on Secondary Prevention through Intervention to Reduce Events (EUROASPIRE) I-III surveys indicate that risk factors remain independent predictors of cardiovascular mortality in CAD patients [4]. The conclusion from another 5-year follow-up survey is that smoking cessation, providing advice on diet and ensuring optimal pharmacological treatment are crucial factors in reducing mortality in patients who have suffered myocardial infarction (MI) [5]. Thus, the highest priority for preventive cardiology was given to patients with established CAD [6].

The Cracovian Program for Secondary Prevention of Ischemic Heart Disease was launched in $1996[7,8]$. The main goal of the program was to assess and improve the quality of medical care in the field of secondary CAD prevention. Later, the same centers took part in the EUROASPIRE surveys [9]. These projects allowed the assessment of temporal changes in the implementation of recommendations as well as international comparisons [9-11]. However, not much is known about the relation between types of acute coronary syndrome (MI vs. unstable angina [UA]) and the quality of secondary prevention in Poland. It is also not known whether CAD patients who have undergone a myocardial revascularization procedure receive better quality medical care than non-revascularized patients. The aim of the present study was to assess the recent status of implementation of the guidelines for secondary prevention in everyday clinical practice by assessing control of the main risk factors and the cardioprotective medication prescription rates in patients after hospitalization for CAD.

\section{Methods}

The study groups and the methods used in the Cracovian Program for Secondary Prevention of Ischemic Heart Disease and Polish part of EUROASPIRE surveys were described in earlier reports $[10,11]$. A brief description is given below.

Five hospitals with cardiology departments, serving the city and its surrounding districts in the southern part of Poland participated in the study. Total population of this area is about $1,200,000$ inhabitants. In each department, medical records of consecutive patients hospitalized from January 1 2010 to April 312012 due to acute MI (first or recurrent, no prior percutaneous coronary intervention $[\mathrm{PCI}]$ or coronary artery bypass grafting [CABG]), UA (first or recurrent, no prior PCI or CABG), PCI (first, no prior CABG) or scheduled for $\mathrm{CABG}$ (first) were reviewed and patients aged $\leq$ 80 years were identified retrospectively excluding those who had died during their in-hospital stay and those who were scheduled for CABG combined 
Table 1. Characteristics of the study population.

\begin{tabular}{|c|c|c|c|c|c|c|}
\hline & $\begin{array}{c}\text { MI } \\
(n=267)\end{array}$ & $\begin{array}{c}\text { UA } \\
(n=191)\end{array}$ & $\begin{array}{c}\mathrm{PCl} \\
(\mathrm{n}=99)\end{array}$ & $\begin{array}{c}\text { CABG } \\
(n=38)\end{array}$ & $\mathbf{P}$ & $\begin{array}{c}\text { Total } \\
(n=595)\end{array}$ \\
\hline Age [years] & $62.8 \pm 9.4$ & $63.2 \pm 9.0$ & $61.0 \pm 7.7$ & $65.9 \pm 8.2$ & $<0.05$ & $62.8 \pm 9.0$ \\
\hline Sex: & & & & & $<0.05$ & \\
\hline Men & $66.3 \%$ & $58.6 \%$ & $78.8 \%$ & $78.9 \%$ & & $66.7 \%$ \\
\hline Women & $33.7 \%$ & $41.4 \%$ & $21.2 \%$ & $21.1 \%$ & & $33.3 \%$ \\
\hline Duration of education* [years] & $11.5 \pm 3.2$ & $12.4 \pm 3.6$ & $11.3 \pm 2.8$ & $11.3 \pm 3.1$ & 0.08 & $11.8 \pm 3.3$ \\
\hline Practice setting*: & & & & & 0.23 & \\
\hline Hospital outpatient clinics & $57.4 \%$ & $53.2 \%$ & $46.9 \%$ & $57.7 \%$ & & $53.8 \%$ \\
\hline Outpatient clinics & $29.1 \%$ & $34.7 \%$ & $39.5 \%$ & $38.5 \%$ & & $33.8 \%$ \\
\hline Private cardiology practices & $8.8 \%$ & $10.5 \%$ & $13.6 \%$ & $3.9 \%$ & & $10.0 \%$ \\
\hline No regular health check-up & $4.7 \%$ & $1.6 \%$ & $0.0 \%$ & $0.0 \%$ & & $2.4 \%$ \\
\hline Specialization of the physician*: & & & & & 0.31 & \\
\hline Cardiologist & $87.2 \%$ & $93.5 \%$ & $85.2 \%$ & $96.2 \%$ & & $89.4 \%$ \\
\hline General practitioner & $12.2 \%$ & $5.5 \%$ & $14.8 \%$ & $3.8 \%$ & & $10.3 \%$ \\
\hline Not known & $0.7 \%$ & $0.0 \%$ & $0.0 \%$ & $0.0 \%$ & & $0.3 \%$ \\
\hline Employed* & $20.3 \%$ & $17.1 \%$ & $25.9 \%$ & $19.2 \%$ & 0.50 & $20.4 \%$ \\
\hline
\end{tabular}

*Among subjects who participated in the follow-up examination, as declared by the patients; CABG — coronary artery bypass grafting; $\mathrm{MI}$ - myocardial infarction; $\mathrm{PCl}$ — percutaneous coronary intervention; UA — unstable angina

with valve surgery. If a patient was hospitalized more than once within the study period, only the first hospitalization was accepted as an index event. The medical records of patients fulfilling the inclusion criteria were analyzed using the standardized data collection form.

Participants were invited to take part in the follow-up examination 6-18 months after discharge. Data on demographic characteristics, personal history of CAD, smoking status, blood pressure, fasting glucose, plasma lipids, and prescribed medications were obtained using a standardized data collection form. The patients' height and weight were measured in a standing position without shoes and heavy outer garments using standard scales with a vertical ruler. Body mass index (BMI) was calculated according to the following formula: $\mathrm{BMI}=$ weight $[\mathrm{kg}] /(\text { height }[\mathrm{m}])^{2}$. Blood pressure was measured twice, on the right arm in a sitting position after at least 5 min of rest. For plasma lipid and glucose measurements a fasting venous blood sample was taken between 7:30 and 8:30 in the morning. For the present report, results of the analyses which were done no later than $4 \mathrm{~h}$ after blood collection were used. Low density lipoprotein-cholesterol (LDL-C) levels were calculated according to Friedewald formula.

We also calculated the secondary prevention coefficient: for each risk factor controlled (not smoking, blood pressure $<140 / 90 \mathrm{~mm} \mathrm{Hg}$, LDL-C $<1.8 \mathrm{mmol} / \mathrm{l}$, glycated hemoglobin $\left[\mathrm{HbA}_{1 \mathrm{c}}\right]<7.0 \%$,
BMI $<25 \mathrm{~kg} / \mathrm{m}^{2}$ ) during the follow-up interview one point was given. Additionally, one point was given for taking an antiplatelet agent and an angiotensin converting enzyme inhibitor (ACEI) or a sartan. Thus, the secondary prevention coefficient could vary from 1 to 7 . The survey protocol was approved by the institutional Bioethics Committee.

\section{Statistical analysis}

Categorical variables were reported as percentages and continuous variables as means \pm standard deviation. The Pearson $\chi^{2}$ test was applied to all categorical variables. Normally distributed continuous variables were compared by using the Student's t test or analysis of variance. Variables without normal distributions were evaluated using the Mann-Whitney U test or the Kruskal-Wallis analysis of variance. Stepwise multivariate analysis was performed using the multivariate regression analysis as implemented in the STATISTICA 8.0 software (StatSoft INC., Tulsa, USA). Adjusted $\mathrm{R}^{2}$ statistic was used as an indicator of the best statistical model. A 2 -tailed $\mathrm{p}$ value $<0.05$ was regarded as indicating statistical significance.

\section{Results}

The medical records of 595 patients were reviewed and included in the analyses. The mean age, sex and proportion of men to women by survey are presented in Table 1 . The patients from the PCI 
Table 2. Proportions of hospital records with available information on risk factors.

\begin{tabular}{lcccccc}
\hline & MI & UA & PCI & CABG & P & Total \\
\hline Smoking* & $92.5 \%$ & $88.5 \%$ & $95.0 \%$ & $92.1 \%$ & 0.25 & $91.6 \%$ \\
Hypertension* $_{\text {Blood pressure** }}$ & $96.6 \%$ & $97.9 \%$ & $96.0 \%$ & $97.4 \%$ & 0.77 & $97.0 \%$ \\
Dyslipidemia* & $98.9 \%$ & $98.4 \%$ & $96.0 \%$ & $100.0 \%$ & 0.21 & $98.3 \%$ \\
Total cholesterol** & 84.35 & $82.2 \%$ & $92.9 \%$ & $89.5 \%$ & 0.08 & $85.4 \%$ \\
Diabetes* & $75.7 \%$ & $78.0 \%$ & $66.7 \%$ & $73.7 \%$ & 0.20 & $74.8 \%$ \\
Weight and height** & $98.5 \%$ & $100.0 \%$ & $98.0 \%$ & $100.0 \%$ & 0.26 & $99.0 \%$ \\
\hline
\end{tabular}

*Any information in the medical record about risk factor prior to hospitalization; **Measurement during hospitalization; CABG — coronary artery bypass grafting; $\mathrm{Ml}$ - myocardial infarction; $\mathrm{PCl}$ - percutaneous coronary intervention; UA — unstable angina

Table 3. Prescription rates of cardioprotective drugs at discharge.

\begin{tabular}{lcccccc}
\hline & MI & UA & PCI & CABG & P & Total \\
\hline Antiplatelets & $99.3 \%$ & $99.0 \%$ & $100.0 \%$ & $100.0 \%$ & 0.72 & $99.3 \%$ \\
Beta-blockers & $83.2 \%$ & $84.8 \%$ & $95.0 \%$ & $76.3 \%$ & 0.01 & $85.2 \%$ \\
ACEl/sartans & $79.8 \%$ & $89.0 \%$ & $97.0 \%$ & $73.7 \%$ & $<0.001$ & $85.2 \%$ \\
Calcium antagonists & $20.2 \%$ & $31.4 \%$ & $23.2 \%$ & $18.4 \%$ & 0.04 & $24.2 \%$ \\
Diuretics & $36.0 \%$ & $43.5 \%$ & $45.5 \%$ & $39.5 \%$ & 0.26 & $40.2 \%$ \\
Lipid lowering drugs & $92.1 \%$ & $95.8 \%$ & $99.0 \%$ & $84.2 \%$ & $<0.01$ & $93.9 \%$ \\
Antidiabetic agents & $28.5 \%$ & $23.0 \%$ & $30.3 \%$ & $34.2 \%$ & 0.35 & $27.4 \%$ \\
Anticoagulants & $24.3 \%$ & $23.0 \%$ & $9.1 \%$ & $34.2 \%$ & $<0.01$ & $22.0 \%$ \\
\hline
\end{tabular}

ACEI - angiotensin converting enzyme inhibitors; CABG — coronary artery bypass grafting; $\mathrm{MI}$ - myocardial infarction; PCl — percutaneous coronary intervention; UA - unstable angina

group were the youngest, whereas the proportion of women was the highest in the UA group.

The proportions of medical records with available information on risk factors are presented in the Table 2. We found no major differences in the proportions of medical records with available information on risk factors between index diagnoses with the exception of weight and height. The proportion of medical records with available information on weight and height was significantly lower in the CABG and MI groups when compared with the other index diagnoses. Cardioprotective drugs prescription rates at discharge are shown in Table 3. The prescription rate of beta-blockers (BB), ACEI or sartans, calcium antagonists, lipid-lowering drugs, and anticoagulants differed between the index diagnoses, whereas the prescription rate of antiplatelets and diuretics were similar across groups.

Out of the 595 invited patients $380(63.9 \%)$ participated in the follow-up examination 6-18 months after discharge from hospital. The participation rate differed significantly across the index events: MI group — 55.4\%, UA group - 65.4\%, PCI group $-81.8 \%$, CABG group $-68.4 \%(\mathrm{p}<0.05)$. No significant differences were found between men and women $(63.5 \%$ vs. $64.6 \%, \mathrm{p}=\mathrm{NS})$. There were no significant differences in mean age of those who underwent a follow-up examination and those who did not $(62.6 \pm 8.6$ years vs. $63.2 \pm 9.7$ years, $\mathrm{p}=\mathrm{NS}$ ).

The study participants did not differ significantly between the index events in respect of the duration of education, employment, practice setting, and the specialization of the physician deciding on the course of management (Table 1). Overall, $33.9 \%$ of the study participants declared they had been advised to participate in a rehabilitation/ secondary prevention program following the index hospitalization (MI 39.2\%, UA $32.8 \%$, PCI $21.0 \%$, CABG $50.0 \% ; \mathrm{p}<0.05)$ and $30.5 \%$ participated in a rehabilitation/secondary prevention program following the index hospitalization. However, only $28.2 \%$ took part in at least half of the planned sessions (MI $32.4 \%$, UA $25.6 \%$, PCI $17.3 \%$, CABG $50.0 \%$; $<0.05)$.

We found that $20.3 \%$ of the participants smoked, $47.2 \%$ had high blood pressure, $72.8 \%$ 
Table 4. Proportions of patients who did not reach treatment goals 6-18 months after discharge.

\begin{tabular}{|c|c|c|c|c|c|c|}
\hline & MI & UA & $\mathrm{PCl}$ & CABG & $\mathbf{P}$ & Total \\
\hline Smoking & $17.6 \%$ & $22.4 \%$ & $22.2 \%$ & $19.2 \%$ & 0.75 & $20.3 \%$ \\
\hline $\mathrm{BP} \geq 140 / 90 \mathrm{~mm} \mathrm{Hg}$ & $43.5 \%$ & $46.3 \%$ & $54.3 \%$ & $50.0 \%$ & 0.47 & $47.2 \%$ \\
\hline LDL-C $\geq 1.8 \mathrm{mmol} / \mathrm{L}$ & $71.1 \%$ & $72.6 \%$ & $73.8 \%$ & $80.0 \%$ & 0.83 & $72.8 \%$ \\
\hline $\mathrm{HbA}_{1 \mathrm{c}} \geq 7.0 \%$ & $16.2 \%$ & $13.3 \%$ & $15.0 \%$ & $8.6 \%$ & 0.20 & $13.9 \%$ \\
\hline $\mathrm{BMI} \geq 25 \mathrm{~kg} / \mathrm{m}^{2}$ & $79.1 \%$ & $80.5 \%$ & $84.0 \%$ & $76.9 \%$ & 0.80 & $80.4 \%$ \\
\hline $\mathrm{BMI} \geq 30 \mathrm{~kg} / \mathrm{m}^{2}$ & $38.5 \%$ & $40.7 \%$ & $39.5 \%$ & $15.4 \%$ & 0.11 & $37.8 \%$ \\
\hline
\end{tabular}

$\mathrm{BMI}$ - body mass index; $\mathrm{BP}$ - blood pressure; $\mathrm{HbA}_{1 \mathrm{c}}$ - glycated hemoglobin; LDL-C — low density lipoprotein cholesterol; CABG — coronary artery bypass grafting; $\mathrm{MI}$ — myocardial infarction; $\mathrm{PCl}$ — percutaneous coronary intervention; UA — unstable angina

Table 5. Proportions of patients taking cardioprotective drugs 6-18 months after discharge from hospital.

\begin{tabular}{lcccccc}
\hline & MI & UA & PCI & CABG & P & Total \\
\hline Antiplatelets & $91.9 \%$ & $84.8 \%$ & $93.8 \%$ & $88.5 \%$ & 0.13 & $89.7 \%$ \\
Beta-blockers & $80.8 \%$ & $77.7 \%$ & $88.9 \%$ & $88.5 \%$ & 0.15 & $81.8 \%$ \\
ACEl/sartans & $76.4 \%$ & $81.6 \%$ & $76.5 \%$ & $76.9 \%$ & 0.73 & $78.2 \%$ \\
Calcium antagonists & $17.6 \%$ & $31.2 \%$ & $22.2 \%$ & $19.2 \%$ & 0.06 & $23.2 \%$ \\
Diuretics & $37.2 \%$ & $45.6 \%$ & $40.7 \%$ & $38.5 \%$ & 0.56 & $40.8 \%$ \\
Lipid lowering drugs & $83.1 \%$ & $76.8 \%$ & $87.7 \%$ & $88.5 \%$ & 0.18 & $82.4 \%$ \\
Antidiabetic agents & $26.4 \%$ & $27.3 \%$ & $35.4 \%$ & $32.0 \%$ & 0.50 & $29.0 \%$ \\
Anticoagulants & $4.9 \%$ & $5.0 \%$ & $10.1 \%$ & $16.0 \%$ & 0.10 & $6.8 \%$ \\
\hline
\end{tabular}

ACEI — angiotensin converting enzyme inhibitors; CABG — coronary artery bypass grafting; $\mathrm{MI}$ - myocardial infarction; PCI — percutaneous coronary intervention; UA - unstable angina

Table 6. Proportions of smokers (before the index hospitalization or at the time of the follow-up examination) being ever instructed by a physician on smoking cessation (as declared by the patients).

\begin{tabular}{lcccccc}
\hline & MI & UA & PCI & CABG & P & Total \\
\hline Oral advice & $68.5 \%$ & $74.4 \%$ & $63.6 \%$ & $44.4 \%$ & 0.36 & $67.7 \%$ \\
Advice using printed materials & $31.4 \%$ & $34.3 \%$ & $36.4 \%$ & $33.3 \%$ & 0.98 & $33.3 \%$ \\
Referral to a smoking cessation clinic & $22.2 \%$ & $20.6 \%$ & $22.7 \%$ & $12.5 \%$ & 0.93 & $21.1 \%$ \\
Nicotine replacement therapy & $11.1 \%$ & $20.6 \%$ & $13.6 \%$ & $0.0 \%$ & 0.38 & $13.6 \%$ \\
Bupropion or varenicline & $11.1 \%$ & $9.1 \%$ & $4.6 \%$ & $0.0 \%$ & 0.63 & $8.3 \%$ \\
Advice on other methods & $11.4 \%$ & $8.8 \%$ & $4.6 \%$ & $0.0 \%$ & 0.62 & $8.3 \%$ \\
\hline
\end{tabular}

CABG — coronary artery bypass grafting; $\mathrm{MI}$ - myocardial infarction; $\mathrm{PCl}$ - percutaneous coronary intervention; UA — unstable angina

high LDL-C level, $13.9 \%$ had $\mathrm{HbA}_{1 \mathrm{c}} \geq 7.0 \%$, and $37.8 \%$ were obese $6-18$ months after discharge (Table 4). No significant relation between the index events and the control of risk factors was found. Proportion of patients taking antiplatelets, $\mathrm{BB}, \mathrm{ACEI} /$ sartans, diuretics, lipid-lowering drugs, and antidiabetic agents did not differ significantly between the index groups (Table 5). The only significant difference was higher proportion of patients from the UA group taking calcium antagonists as compared with the MI group ( $\mathrm{p}<0.01)$, and higher proportion of $\mathrm{CABG}$ participants taking anticoagu- lants when compared with the MI $(\mathrm{p}<0.05)$ and UA $(\mathrm{p}<0.05)$ groups.

The proportions of smokers being ever instructed on methods of smoking cessation are presented in Table 6 , whereas the proportions of patients being ever instructed in healthy diet are presented in Table 7 . The study groups did not differ in proportions of participants instructed in smoking cessation methods or healthy diet.

The mean secondary prevention coefficient was $4.35 \pm 1.08$. In the univariate analysis, the secondary prevention coefficient was related 
Table 7. Proportions of patients being ever instructed by a physician in healthy diet (as declared by the patients).

\begin{tabular}{lcccccc}
\hline & MI & UA & PCI & CABG & P & Total \\
\hline Reduction of salt intake & $73.8 \%$ & $78.7 \%$ & $81.5 \%$ & $80.8 \%$ & 0.54 & $77.5 \%$ \\
Reduction of fat intake & $80.7 \%$ & $84.4 \%$ & $87.7 \%$ & $88.5 \%$ & 0.50 & $84.0 \%$ \\
Increase in unsaturated fats intake & $77.4 \%$ & $81.2 \%$ & $86.4 \%$ & $88.5 \%$ & 0.29 & $81.3 \%$ \\
Reduction of calories intake & $71.2 \%$ & $76.2 \%$ & $70.4 \%$ & $76.9 \%$ & 0.71 & $73.1 \%$ \\
Increase in vegetables and fruits intake & $78.1 \%$ & $79.5 \%$ & $86.4 \%$ & $84.6 \%$ & 0.44 & $80.8 \%$ \\
Increase in fish intake & $67.8 \%$ & $68.9 \%$ & $77.8 \%$ & $80.8 \%$ & 0.26 & $71.2 \%$ \\
\hline
\end{tabular}

CABG - coronary artery bypass grafting; $\mathrm{MI}$ - myocardial infarction; $\mathrm{PCl}$ - percutaneous coronary intervention; UA — unstable angina

to participation in the rehabilitation/secondary prevention program following the index hospitalization, yet not to the index event (Table 8). In a multivariate model, the secondary prevention coefficient was related to the patient's age, education and participation in a rehabilitation/secondary prevention program following the index hospitalization (Table 9).

\section{Discussion}

In general, our results did not show a big improvement in the management of patients after hospitalization for $\mathrm{CAD}$ as compared to the previous survey which was finished in 2012 [11]. As in the previous surveys we found considerable potential for further reduction of cardiovascular risk in CAD patients $[8,10,11]$.

Unfortunately, no study published in recent years was designed to assess secondary prevention of CAD outside Krakow. However, some recently published data from registries of patients hospitalized due to acute coronary syndromes are available $[12,13]$. In a nation-wide registry of acute coronary syndrome hospitalizations it was estimated that the average prescription rate at discharge for aspirin and lipid lowering agents was slightly below $90 \%$, and for BB and ACEI below 80\% [12]. In 3,564 patients hospitalized for ST-elevation MI in Greater Poland, the prescription rates were $96 \%$ for antiplatelet agents, $74 \%$ for BB, $58 \%$ for ACEI and $90 \%$ for statins [13]. It should be stressed that the prescription rates of cardiopreventive medications in Poland are similar to the average prescription rates in centers participating in the EUROASPIRE III Survey [9], and much higher compared to centers from high-income countries participating in the PURE Study [14].

The present results confirm the observations of the survey carried out in 2006-2007 which suggested no major sex-related difference in the pro-
Table 8. The secondary prevention coefficient (SPC) values according to subgroups of patients.

\begin{tabular}{|c|c|c|}
\hline Subgroup & SPC & $\mathbf{P}$ \\
\hline Age: & & 0.14 \\
\hline$<60$ years & $4.24 \pm 1.11$ & \\
\hline $60-70$ years & $4.33 \pm 1.07$ & \\
\hline$\geq 70$ years & $4.54 \pm 1.05$ & \\
\hline Sex: & & 0.14 \\
\hline Men & $4.41 \pm 1.06$ & \\
\hline Women & $4.24 \pm 1.09$ & \\
\hline Duration of education: & & 0.09 \\
\hline$\leq 11$ years & $4.27 \pm 1.09$ & \\
\hline$>11$ years & $4.47 \pm 1.08$ & \\
\hline Index diagnosis: & & 0.58 \\
\hline Myocardial infarction & $4.41 \pm 1.16$ & \\
\hline Unstable angina & $4.36 \pm 1.08$ & \\
\hline $\mathrm{PCl}$ & $4.21 \pm 0.94$ & \\
\hline CABG & $4.46 \pm 1.14$ & \\
\hline Practice setting: & & 0.37 \\
\hline Hospital outpatient clinics & $4.42 \pm 1.08$ & \\
\hline Outpatient clinics & $4.21 \pm 1.07$ & \\
\hline Private cardiology practices & $4.48 \pm 1.03$ & \\
\hline No regular health check-up & $4.38 \pm 1.51$ & \\
\hline Specialization of the physician: & & 0.08 \\
\hline Cardiologist & $4.39 \pm 1.10$ & \\
\hline General practitioner & $4.05 \pm 0.97$ & \\
\hline Professionally active & $4.34 \pm 0.97$ & 0.93 \\
\hline Professionally inactive & $4.36 \pm 1.12$ & \\
\hline $\begin{array}{l}\text { Rehabilitation/secondary } \\
\text { prevention program: }\end{array}$ & & $<0.05$ \\
\hline Participated & $4.55 \pm 1.10$ & \\
\hline Not participated & $4.28 \pm 1.07$ & \\
\hline Total & $4.35 \pm 1.08$ & \\
\hline
\end{tabular}

CABG - coronary artery bypass grafting, $\mathrm{PCl}$ - percutaneous coronary intervention

portions of patients who achieved recommended treatment targets in secondary prevention [15]. We also showed that older patients (age $\geq 70$ years) 
Table 9. Variables related to the value of the secondary prevention coefficient in the multivariate analysis.

\begin{tabular}{lcc}
\hline & Beta \pm standard error & P \\
\hline Age [years] & $0.15 \pm 0.05$ & 0.01 \\
Participation in a rehabilitation/secondary prevention program & $0.11 \pm 0.05$ & $<0.05$ \\
following the index hospitalization (yes: 1, no: 0) & & $<.11 \pm 0.05$ \\
Duration of education [years] & $0.08 \pm 0.05$ & 0.11 \\
Sex (male: 1, female: 0) & $-0.07 \pm 0.05$ & 0.18 \\
Practice setting (outpatient clinics: 1, other practice settings: 0) & $0.06 \pm 0.05$ & 0.24 \\
Specialization of the physician (cardiologist: 1, general practitioner: 0) & & \\
\hline
\end{tabular}

smoked less frequently compared to patients aged $<60$ [15]. On the other hand, fewer patients aged $\geq 70$ years had blood pressure $<140 / 90 \mathrm{~mm} \mathrm{Hg}$ when compared with younger subjects. No major age-related difference in respect to the other main risk factors or prescriptions rates of cardioprotective medications was found [15]. Indeed, the present results confirm that in general, older age (at least up to 80 years) is not related to lower standard of medical care in the field of secondary prevention.

It should be emphasized that the present results still suggest insufficient control over all main cardiovascular risk factors. As one of the important determinants of reaching the treatment targets is participation in the secondary prevention/cardiac rehabilitation programs, the finding that the low and decreasing proportion of patients had been advised to participate in the secondary prevention program/cardiac rehabilitation does not allow being optimistic. Indeed, in the previous report we showed that the proportion of patients who were advised to participate in such programs was 53.9\% in $2005-2006$ and $47.1 \%$ in $2010-2011$, whereas the proportions of patients who finally participated in a rehabilitation/secondary prevention program were $35.9 \%$ and $33.3 \%$, respectively [11]. It was shown that such programs result in better control of risk factors and improve prognosis [16-18]. Indeed, it seems that a higher participation rate in the secondary prevention/cardiac rehabilitation programs could result in better control of risk factors. Itshould be also stressed that the improved cooperation between hospital and outpatient clinic staff, as well as better access to a cardiologist in case of any suspicion of heart-related problems could further improve the patients' prognosis. Recently, experts from the Polish Cardiac Society described the "Optimal Model of Comprehensive Rehabilitation and Secondary Prevention", wide implementation of which in Poland could be related to a decrease in the number of deaths by 3,389 , in the number of MIs by 3,872, in the number of myocardial revascularization procedure by 13,499 , and in the number of cardiac hospitalizations by 23,182 yearly [19].

\section{Limitations of the study}

The present study has some limitations. Firstly, we were unable to assess the impact of secondary prevention guidelines on the risk of cardiovascular complications. Secondly, our study participants were not representative of all CAD patients. Participants were limited to those who had experienced an acute CAD event or had undergone a revascularization procedure. Therefore, our results should not be directly applied to other CAD patients. Finally, we did not analyze the doses of cardioprotective drugs taken by the patients. It is possible that blood pressure, cholesterolemia, and glycemia were not controlled in some cases due to insufficient doses of the drugs prescribed. It should also be pointed out that we had no information on the patients' compliance with instructions regarding prescriptions. It is reasonable to suspect that some patients had been taking their medications irregularly.

\section{Conclusions}

Our data provide evidence that there is a considerable potential for further reduction of cardiovascular risk in CAD patients. Our results suggest that increasing the participation rate in rehabilitation/secondary prevention programs may improve the implementation of the secondary prevention guidelines.

\section{Acknowledgements}

The project was supported from the grant of the Polish National Science Center (decision No DEC-2011/03/B/NZ7/06101).

\section{Conflict of interest: None declared}




\section{References}

1. WHO, World Health Organization. The World Health Report. WHO, Geneva 2008. http://www.who.int/whr/2008/whr08_en.pdf.

2. World Health Organization Regional Office for Europe (HFA-DB), European health for all database. April 2014.

3. Rządowa Rada Ludnościowa. Sytuacja Demograficzna Polski. Raport 2011-2012. Warszawa 2012.

4. De Bacquer D, Dallongeville J, Kotseva $\mathrm{K}$ et al. Residual risk of cardiovascular mortality in patients with coronary heart disease: The EUROASPIRE Risk Categories. Int J Cardiol, 2013; 168: 910-914.

5. Simpson CR, Buckley BS, McLernon DJ, Sheikh A, Murphy A, Hannaford PC. Five-year prognosis in an incident cohort of people presenting with acute myocardial infarction. PLoS One, 2011; 6: e26573.

6. European Guidelines on cardiovascular disease prevention in clinical practice (version 2012). The Fifth Joint Task Force of the European Society of Cardiology and Other Societies on Cardiovascular Disease Prevention in Clinical Practice. Eur Heart J, 2012; 33: 1635-1701.

7. Kawecka-Jaszcz K, Pająk A, Jankowski P. Krakow Program for Secondary Prevention of Ischaemic Heart Disease. Part I. Genesis and objectives. Przegl Lek, 2001; 58: 953-955.

8. Jankowski P, Kawecka-Jaszcz K, Pająk A et al. Cracovian program for secondary prevention of ischemic heart disease. Secondary prevention of ischemic heart disease after discharge in 1997-1998 and 1999-2000. Przegl Lek, 2003; 60: 142-146.

9. Kotseva K, Wood D, De Backer GD, De Bacquer D, Pyörälä K, Keil U; The EUROASPIRE Study Group. EUROASPIRE III: A survey on the lifestyle, risk factors and use of cardioprotective drug therapies in coronary patients from 22 European countries. EJCPR, 2009; 16: 121-137.

10. Pajak A, Jankowski P, Kawecka-Jaszcz K et al. Changes in secondary prevention of coronary artery disease in the post-discharge period over the decade 1997-2007. Comparison of Cracovian Pro- gram for Secondary Prevention of Ischaemic Heart Disease and Polish parts of EUROASPIRE II and EUROASPIRE III surveys. Kardiol Pol, 2009; 67: 1353-1359.

11. Jankowski P, Czarnecka D, Łysek R et al. Secondary prevention in patients after hospitalization due to coronary artery disease: What has changed since 2006? Kardiol Pol, 2014; 72: 355-362.

12. Poloński L, Gasior M, Gierlotka M et al. Polish Registry of Acute. Coronary Syndromes (PL-ACS). Characteristics, treatments and outcomes of patients with acute coronary syndromes in Poland. Kardiol Pol, 2007; 65: 861-872.

13. Grajek S, Lesiak M, Araszkiewicz A et al. Short- and longterm mortality in patients with ST-elevation myocardial infarction treated with different therapeutic strategies. Results from WIelkopolska REgional 2002 Registry (WIRE Registry). Kardiol Pol, 2008; 66:154-163.

14. Yusuf S, Islam S, Chow CK et al. Use of secondary prevention drugs for cardiovascular disease in the community in high-income, middle-income, and low-income countries (the PURE Study): A prospective epidemiological survey. Lancet, 2011; 378: 1231-1243.

15. Jankowski P, Czarnecka D, Wolfshaut-Wolak R et al. Age, sex, and secondary prevention of ischaemic heart disease in everyday practice. Kardiol Pol, 2013; 71: 1251-1259.

16. Heran BS, Chen JM, Ebrahim S et al. Exercise-based cardiac rehabilitation for coronary heart disease. Cochrane Database Syst Rev, 2011; 7: CD001800.

17. Brown JP, Clark AM, Dalal H, Welch K, Taylor RS. Patient education in the management of coronary heart disease. Cochrane Database Syst Rev, 2011; 12: CD008895.

18. Wood DA, Kotseva K, Connolly S et al. Nurse-coordinated multidisciplinary, family-based cardiovascular disease prevention programme (EUROACTION) for patients with coronary heart disease and asymptomatic individuals at high risk of cardiovascular disease: A paired, cluster-randomised controlled trial. Lancet, 2008; 371: 1999-2012.

19. Jankowski P, Niewada M, Bochenek A et al. Optimal model of comprehensive rehabilitation and secondary prevention. Kardiol Pol, 2013; 71: 995-1003. 